\title{
Data Flow Diagram (DFD) in Developing Online Product Monitoring System (OPMS) of DTI
}

\author{
Bryan L. Guibijar, MSCS \\ Surigao del Sur State University - San Miguel Campus \\ Brgy. Carromata, 8301 San Miguel, Surigao del Sur, Philippines
}

\begin{abstract}
The paper examined the model of data flow diagram in developing OPMS of Department of Trade and Industry. It based from waterfall model in which descriptive research was applied to the existing product monitoring of DTI. Data from existing monitoring of DTI were interpreted and created system data flow diagram (DFD). The data flow diagram as applied in the analysis of software development and examined top-down method that takes process the input and output of data flows. Thus, the method of developed based on the data flow diagram created will enhance the security and order of the developed online system.
\end{abstract}

KEYWORD: Data Flow Diagram, Data Aging, Security, Development, Input and Output data flows

\section{INTRODUCTION}

Online development dramatically raises issue especially in data flow and controlling of data in and out (Li, H., Sun, X., Shi, P., \& Lam, H. K., 2015). This issue commonly happen in some open source online template in making your own site (Hashem, I. A. T., Yaqoob, I., Anuar, N. B., Mokhtar, S., Gani, A., \& Khan, S. U., 2015). In fact, lots of students were creating their websites in free hosting and ready- made template (Ravichandran, H., Toohil, R., \& Lammi, L., 2014). This leads to catastrophe when comes to data uploading and data downloading. The creation of the Data Flow Diagram in developing an online site will solve the issues. The study aims to provide standard data flow diagram to enhance Input and Output Data flow (Abedjan, Z., Schulze, P., \& Naumann, F., 2014, November).

Data Flow Diagrams are categorized by level, stating with the most basic, level $0-3$ (see figure 1 to figure 3), DFDs get increasingly complex as the level increases, as you build your own data flow diagram, you will need to decide which level your diagram will be. In theory, DFDs could go beyond level 3, but they rarely do, level 3 data flow diagrams are detailed enough that it doesn't usually make sense to break them down further (Bangeter, J., 2017).

\section{RESEARCH DESIGN AND METHODS}

The Study used descriptive research in which standard Data Flow Diagram was applied. Three level in Data flow Diagram was applied in this research. 


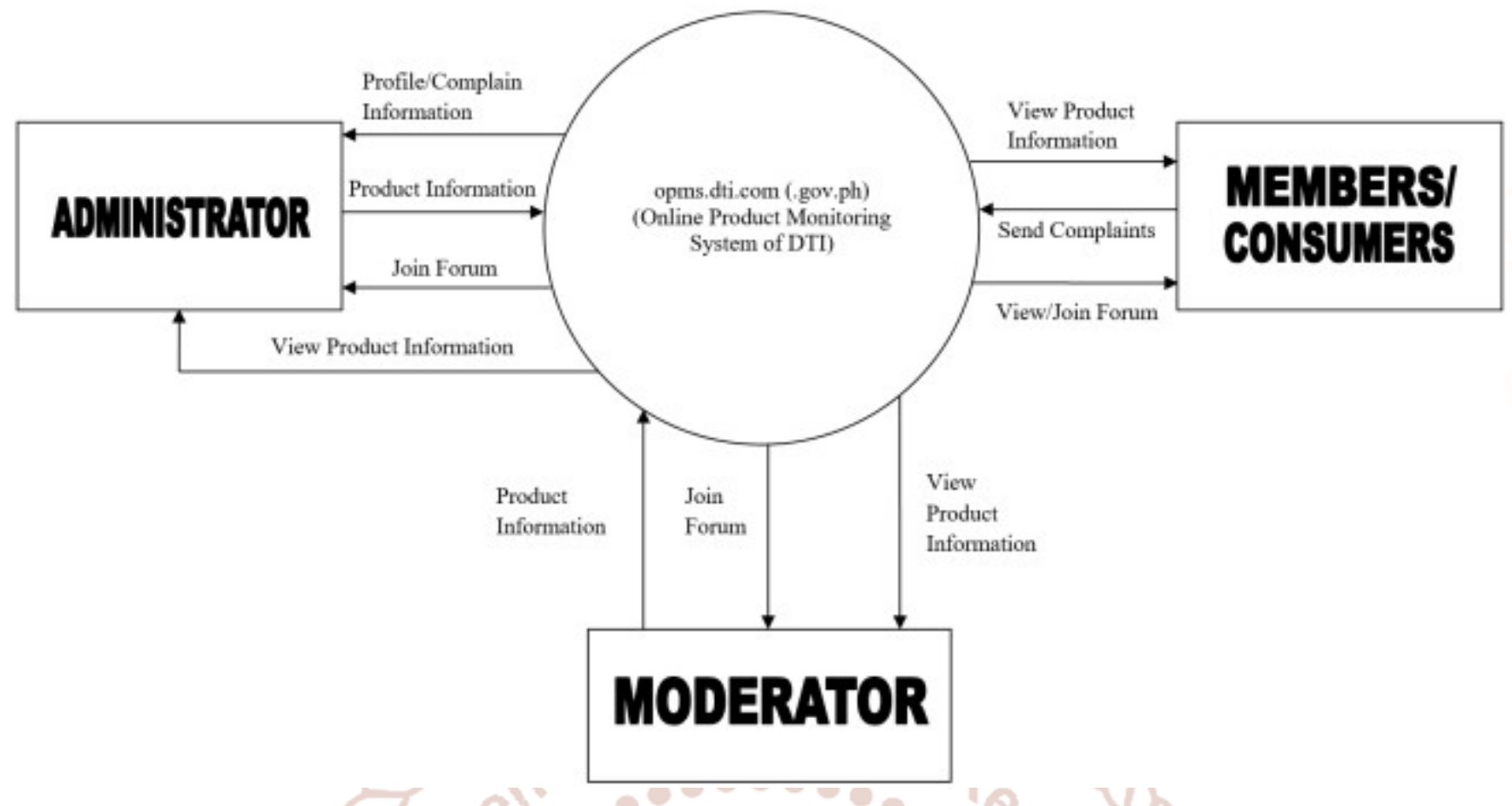

Figure 1. Context level Diagram

Context level diagram shows the level of access right of different users of the system. Administrator access all rights like Profile/Complain Information, Product Information, Join Form and View Product Information. Moderator is a substitute user in case of the absence of the Administrator, the access rights of this user is minimal and that is intended for the primary need of the client user (Members / Consumers). Members / Consumers are the users across the country that will access the viewing of the product information if the market in their place follow the suggested retail price of the commodities and if not they will send complaints according to their actual experiences. Members/Consumers has also the right to access the Forum with different rights, like if you are already registered to the system you might be able to joined the asynchronous conversion with the different members across the country and if not yet register the consumers will still view the minimal conversation of the members.

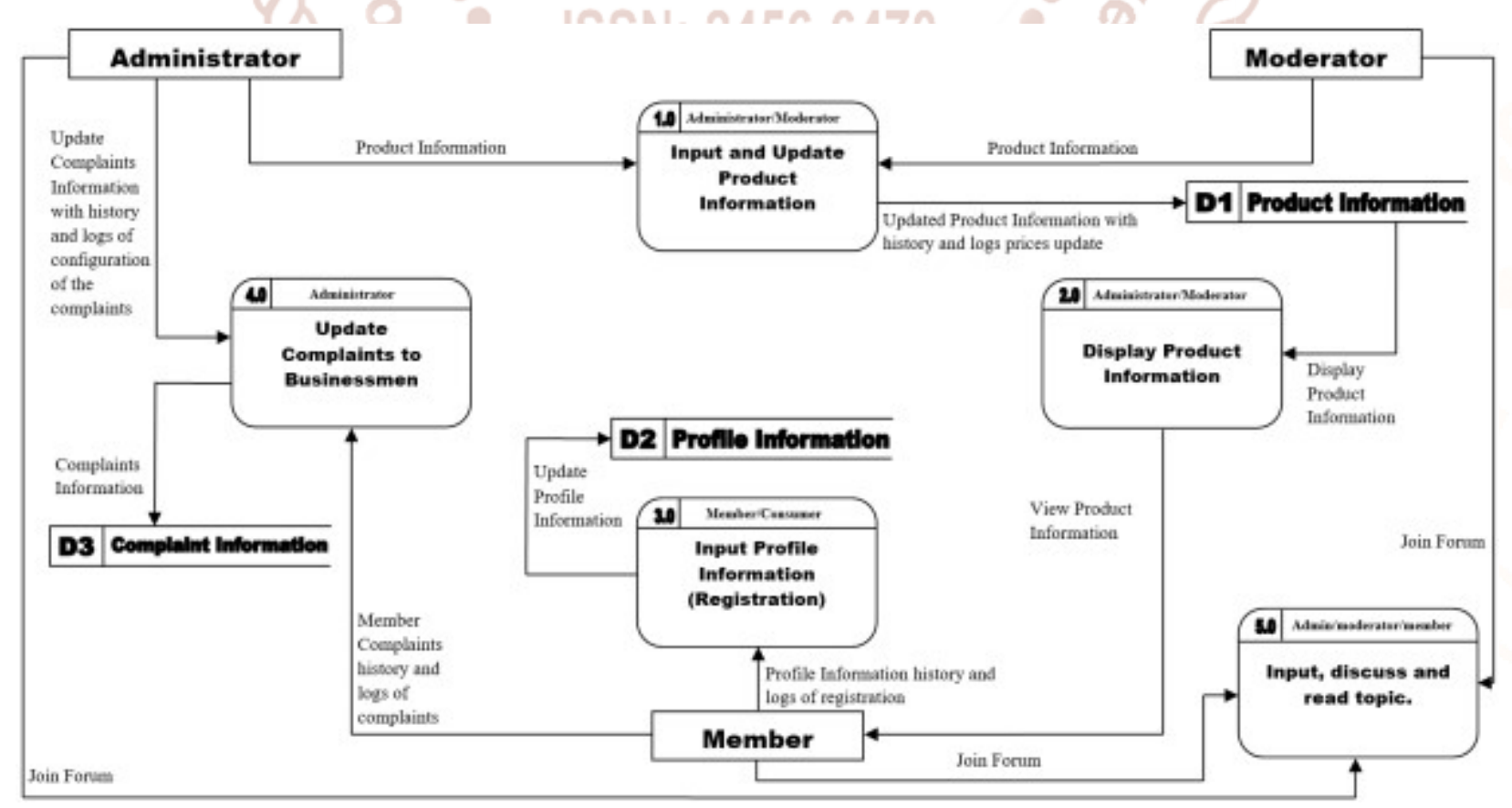

Figure 2. Logical Data Flow Diagram 
Figure 2 shows the more detailed access rights of different users of the system. Logical Data Flow Diagram discuss the most intensive transaction inside the system developed. It defines specifically the user access right with the different module of the system. The modules are numbered from 1.0 to 5.0 labelled with users who have the access right. The figure also labelled if the user is intended for viewing only and if the user is allowed to alter the information.

Figure 3. Hierarchical Input Process Output (H-I-P-O)

The H-I-P-O Hierarchy is being used as an aid during general system design and the output of the general program design is the input for the detailed module design (Stevens, W. P., Myers, G. J., \& Constantine, L. L., 1974). The considerations and techniques presented here are useful for evaluating alternatives for those portions of the system that will be programmed on a computer.

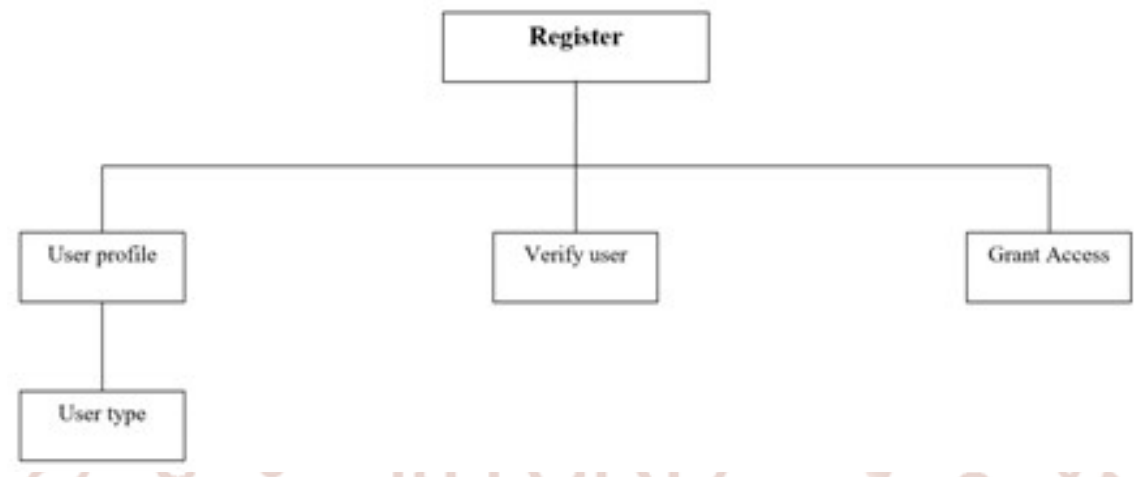

Figure 3.1. H-I-P-O Diagram for Register

The H-I-P-O Diagram for Register, starting in identifying the user type as shown in Figure 1 there are three rectangle compose the Administrator, Moderator and Members / Consumers. It is important to give identity to each users to ensure the accountability of each users. User profile will be provide by the users who register his / herself, then verification and then grant access.

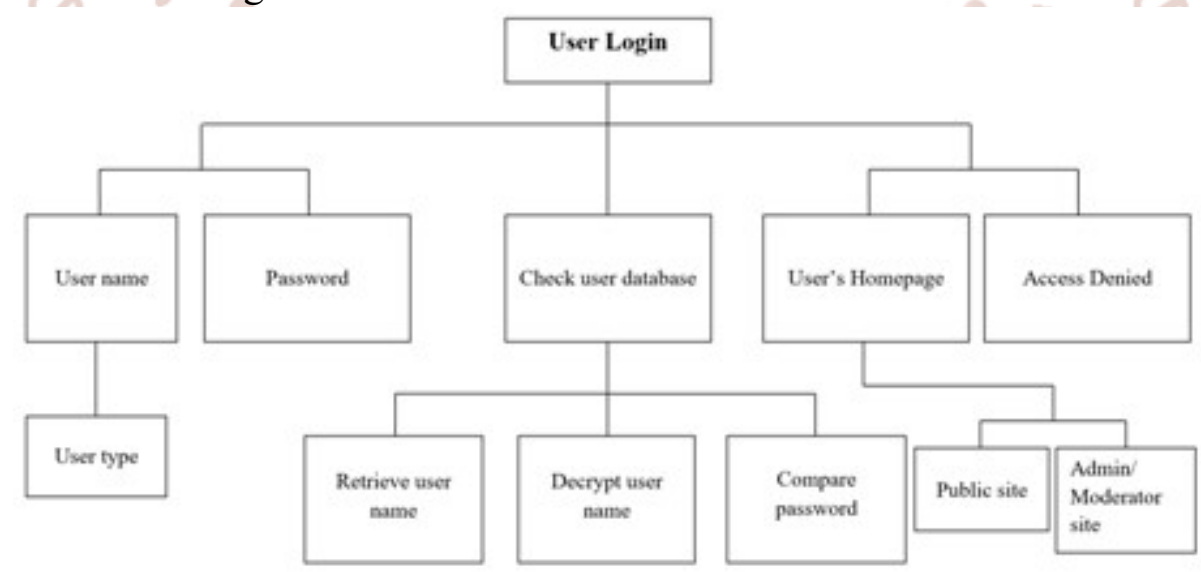

3.2. H-I-P-O Diagram for Access Control

The H-I-P-O Diagram for Access Control, is a design to verify the user type and password as the security to avoid malicious user access. This will also identify the limitation of the user access in every module provide by the system. 


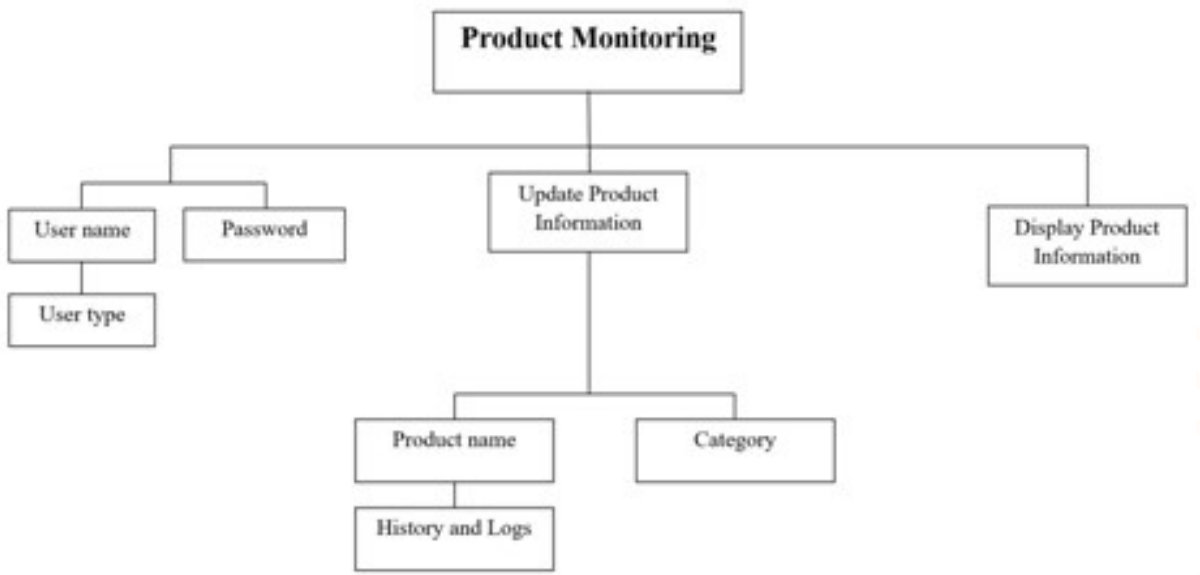

Figure 3.3. H-I-P-O Diagram for Product Monitoring

The H-I-P-O Diagram for Product Monitoring, this is the main display of the developed system and as observed user type is also identify to avoid discrepancy of the display product information. This module the same module as the administrator and moderator change the product information, so that the user type is very important to include.

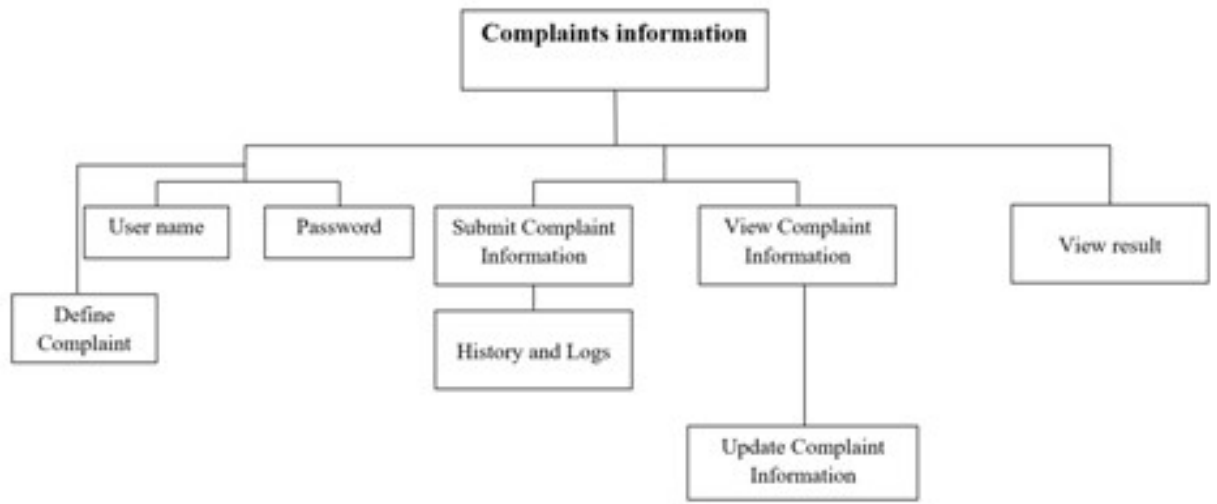

Figure 3.4. H-I-P-O Diagram for Complaint Information

The H-I-P-O Diagram for Complaint Information, this module show the data flow of the complaints submitted by the members and consumers.

\section{RESULTS AND DISCUSSIONS}

Table 1. Data Dictionary

Table 1.1. Answers

\begin{tabular}{|lllll|l|}
\hline Name & Type & Length & Decimals & Allow Null & \\
\hline commentid & int & 11 & 0 & $\square$ & $P_{1}$ \\
\hline author & varchar & 250 & 0 & $\square$ & \\
\hline forumid & int & 11 & 0 & $\square$ \\
\hline answer & varchar & 10000 & 0 & $\square$ \\
\hline datecreated & datetime & 0 & 0 & $\mid \square$ & \\
\hline
\end{tabular}

Table 1.2. Commodity Type

\begin{tabular}{lllll|l}
\hline Name & Type & Length & Decimals & Allow Null & \\
\hline comid & int & 11 & 0 & $\square$ & $\otimes_{1}$ \\
\hline description & varchar & 256 & 0 & $\square$ & \\
\hline class & varchar & 5 & 0 & $\square$ &
\end{tabular}


Table 1.3. Complaint Response

\begin{tabular}{|c|c|c|c|c|c|}
\hline Name & Type & Length & Decmols & Alow $N$ ol & \\
\hline - conplarresponseid & $n$ & 11 & 0 & $\square$ & $\rho_{1}$ \\
\hline conclsinid & ink & 11 & 0 & $\square$ & \\
\hline messope & varchas: & 1000 & 0 & $\square$ & \\
\hline froes & varchar: & 100 & 0 & $\square$ & \\
\hline dotecreoked & dxtetime & 0 & 0 & $\square$ & \\
\hline
\end{tabular}

Table 1.4. Complaints

\begin{tabular}{|lllll|l}
\hline Name & Type & Length & Decimals & Allow Null & \\
\hline complainid & int & 11 & 0 & \\
fullname & varchar & 268 & 0 & \\
\hline emal & varchar & 50 & 0 & \\
respondent & varchar & 255 & 0 & \\
\hline respondentaddress & varchar & 256 & 0 & $\square$ \\
\hline description & varchar & 10000 & 0 & $\square$ \\
\hline datecreated & datetime & 0 & 0 & $\square$ \\
\hline
\end{tabular}

Table 1.5. Current Prices

\begin{tabular}{|c|c|c|c|c|c|}
\hline Name & Type & Length & Decimals & Allow Null & \\
\hline cur_priceid & int & 11 & 0 & $\square$ & $\theta_{1}$ \\
\hline productid & int & 11 & 0 & $\square$ & \\
\hline low & float & 10 & 2 & $\square$ & \\
\hline high & float & 10 & 2 & $\square$ & \\
\hline prevaling & float & 10 & 2 & $\square$ & \\
\hline location & varchar & 256 & 0 & $\square$ & \\
\hline remarks & varchar & 1000 & 0 & $\square$ & \\
\hline datecreated & datetime & 0 & 0 & $\square$ & \\
\hline dateupdated & datetime & 0 & 0 & $\checkmark$ & \\
\hline updatedby & varchar & 50 & 0 & $\checkmark$ & \\
\hline$\Xi 0$ & \multicolumn{3}{|c|}{ OF Table 1.6. Forum } & $\mathrm{C}$ & 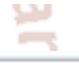 \\
\hline Name & Type & Length & Decimals & Allow Null & \\
\hline ForumId & int & 11 & 0 & $\square$ & $\otimes_{1}$ \\
\hline subject & varchar & 1000 & 0 & $\checkmark$ & \\
\hline Author & int & 11 & 0 & $\checkmark$ & \\
\hline Description & varchar & 1000 & 0 & $\checkmark$ & \\
\hline DateCreated & datetime & 0 & 0 & $\nabla$ & \\
\hline Name & Type & Length & Decimals & Allow Null & \\
\hline memberid & int & 11 & 0 & $\square$ & $P_{1}$ \\
\hline tale & varchar & 255 & 0 & $\sqrt{\square}$ & \\
\hline firstname & varchar & 50 & 0 & $\square$ & \\
\hline lastname & varchar & 50 & 0 & $\square$ & \\
\hline email & varchar & 50 & 0 & $\square$ & \\
\hline occupation & varchar & 128 & 0 & $\nabla$ & \\
\hline username & varchar & 20 & 0 & $\square$ & \\
\hline password & varchar & 20 & 0 & $\square$ & \\
\hline datecreated & datetime & 0 & 0 & $\checkmark$ & \\
\hline dateupdated & datetime & 0 & 0 & $\checkmark$ & \\
\hline
\end{tabular}

Table 1.8. Price Update Logs

\begin{tabular}{|lllll|}
\hline Name & Type & Length & Decimals & Allow Null \\
\hline priceupdatelogid & int & 11 & 0 & $\square$ \\
productid & int & 11 & 0 & $\square$ \\
\hline location & varchar & 256 & 0 & \\
srp & float & 0 & 0 & $\square$ \\
\hline datecreated & datetime & 0 & 0 & $\square$ \\
updatedby & int & 11 & 0 & $\square$ \\
\hline
\end{tabular}


Table 1. Data Dictionary is a design tables accordingly to the data flow diagram in the methodology of the research presented. Hatley, D., \& Pirbhai, I. (2013), stated that there has been growing dissatisfaction with conventional strategies for systems development, and an increasing number of proposals for replacing them with new, more formal approaches.

Figure 4. Entity Relationship Diagram

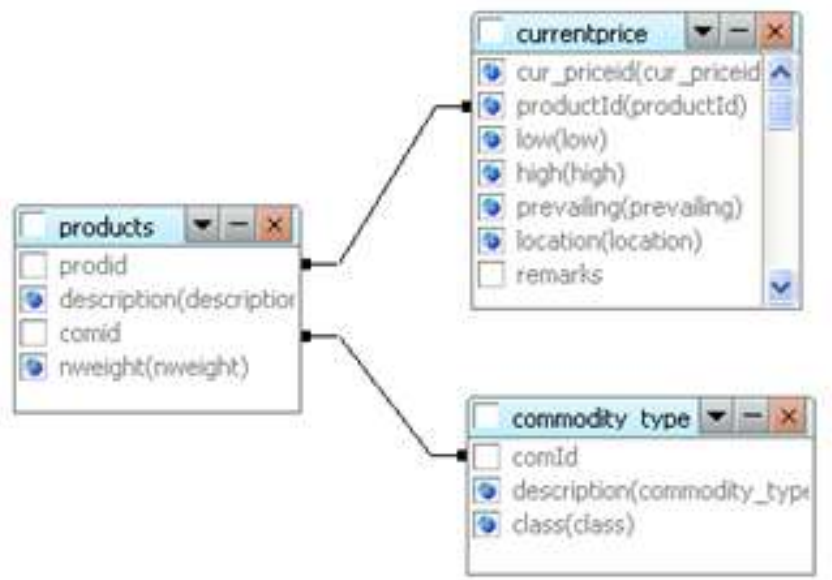

Figure 4.1. products, currentprice and commodity type Relationship (one-to-one)

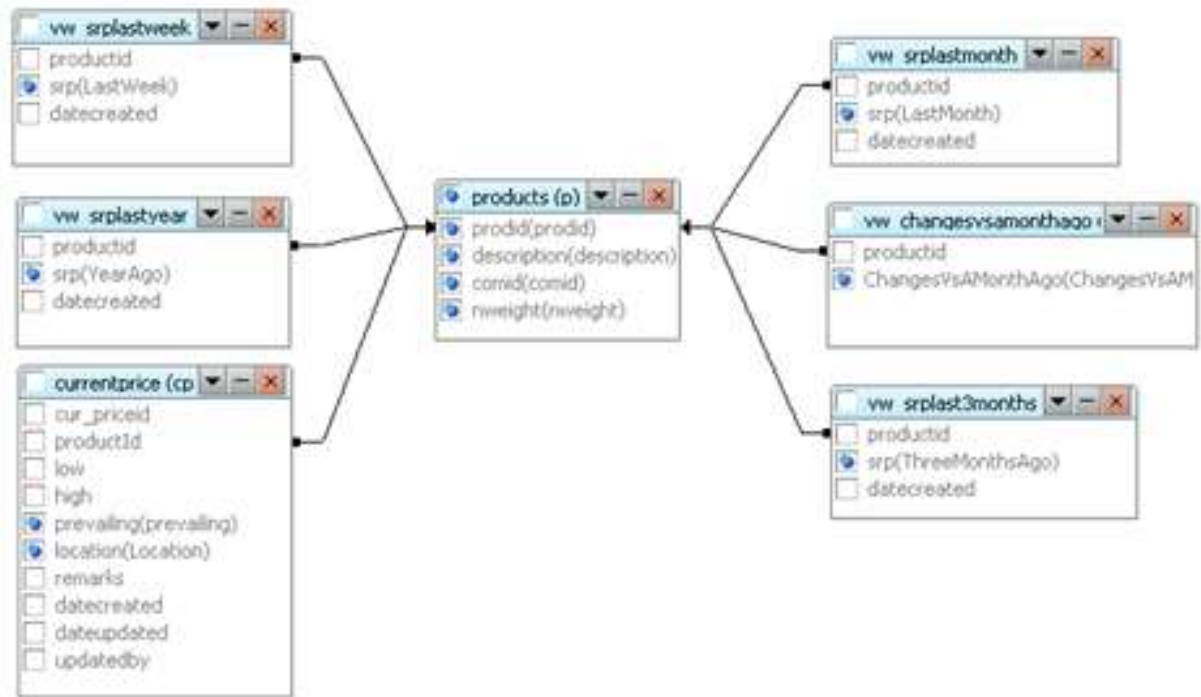

Figure 4.2. products (p) and vw_srplastweek, vw_srplastmonth, vw_srpLast3months, vw_srplastyear and vw_srpchangesvsmonthago views Relationship (one-to-many)

Figure 4. Entity Relationship Diagram, is a data model that represents the logical structure of the database (Rossi, B., 2014).

\section{CONCLUSION}

This study gets the Data Flow Diagram (DFD) in Developing Online Product Monitoring System of DTI. In developing a system it is important that the programmer should create first the data flow of the system, before the development or the system creation will start. As claim in DFDs theory, the level of data flow diagram could go beyond level 3, but rarely do this. Bangeter, J. (July 06, 2017) stated this, this author anticipate already that the data flow diagram can be push through the most intensive definition of the system development and in more specified accordingly and necessarily.

\section{RECOMMENDATION}

It is strongly recommended by the author of this research to use the same method in developing a system. After reading this research you will have some background knowledge on data flow diagrams and how they are categorized, you're ready to build your own DFD. Data flow diagram as applied in 
analysis of software development enhanced the security and order of the developed online system.

\section{REFERENCES}

1) Li, H., Sun, X., Shi, P., \& Lam, H. K. (2015). Control design of interval type-2 fuzzy systems with actuator fault: Sampled-data control approach. Information Sciences, 302, 1-13. Retrieve August 11, 2018 from https://goo.gl/CsHUQq

2) Hashem, I. A. T., Yaqoob, I., Anuar, N. B., Mokhtar, S., Gani, A., \& Khan, S. U. (2015). The rise of "big data" on cloud computing: Review and open research issues. Information Systems, 47, 98-115. Retrieve August 11, 2018 from https://goo.gl/P2Kpei

3) Ravichandran, H., Toohil, R., \& Lammi, L. (2014). U.S. Patent No. 8,843,571. Washington, DC: U.S. Patent and Trademark Office. Retrieve August 11, 2018 from https://goo.gl/sMgivH

4) Liu, S. (2013). Formal Engineering for Industrial Software Development: Using the SOFL Method. Springer Science \& Business Media. Retrieve August 11, 2018 from https://goo.gl/x6x6tu
5) Abedjan, Z., Schulze, P., \& Naumann, F. (2014, November). DFD: Efficient functional dependency discovery. In Proceedings of the 23rd ACM International Conference on Conference on Information and Knowledge Management (pp. 949-958). ACM. Retrieve August 11, 2018 from https://goo.gl/Sgx2Vx

6) Stevens, W. P., Myers, G. J., \& Constantine, L. L. (1974). Structured design. IBM Systems Journal, 13(2), 115-139. Retrieve August 19, 2018 from https://goo.gl/sMVqtf

7) Hatley, D., \& Pirbhai, I. (2013). Strategies for real-time system specification. Addison-Wesley. Retrieve August 19, 2018 from https://goo.gl/Rbs6B4

8) Rossi, B. (2014). Entity relationship diagram. Retrieve August 19, 2018 from https://goo.gl/hYRmte

9) Bangeter, J. (July 06, 2017). Data Flow Diagram Symbols, Types, and Tips. Retrieve August 19, 2018 from https://goo.gl/bHEJi2 